\title{
The Egg Parasitoid Trissolcus basalis uses n-nonadecane, a Cuticular Hydrocarbon from its Stink Bug Host Nezara viridula, to Discriminate Between Female and Male Hosts
}

\author{
Stefano Colazza • Gloria Aquila • Claudio De Pasquale • \\ Ezio Peri • Jocelyn G. Millar
}

Received: 20 February 2007 / Revised: 13 April 2007 / Accepted: 23 April 2007 /

Published online: 27 November 2007

(C) Springer Science + Business Media, LLC 2007

The profiles of cuticular hydrocarbons determined from analyses of hexane extracts of male and female southern green stink bugs, Nezara viridula, that we reported in this manuscript (Table 1 and Fig. 4), are incorrect. During further studies with this system, we determined that most of the alkanes shown in the bell-shaped profiles of hydrocarbons (Fig. 4 and Table 1) were contaminants, probably related to the rearing conditions and materials used. However, the profiles determined by solid phase microextraction (Fig. 5) are indeed accurate representations of the cuticular hydrocarbons. Furthermore, our ongoing studies have shown that the major point of the manuscript is correct, i.e., that n-nonadecane is male-specific, and that this compound is used by the egg parasitoid Trissolcus basalis to discriminate between the traces left by male and female hosts. We are currently repeating all the analyses, fractionations, and bioassays reported in this paper, and the full corrected results will be reported as soon as they are available.

The online version of the original article can be found at http://dx.doi.org/10.1007/s10886-007-9300-7

S. Colazza $(\bowtie) \cdot$ G. Aquila $\cdot$ E. Peri

Department of S.En.Fi.Mi.Zo., Section of Acarology, Entomology and Zoology, Università di Palermo, Palermo, Italy

e-mail: colazza@unipa.it

C. De Pasquale

Department of C.I.S.A.C., Università di Palermo via Archirafi, 38-40-I 90123 Palermo, Italy

J. G. Millar

Department of Entomology, University of California, Riverside, CA 92521, USA 